\title{
Curcumin: A Review of Its' Effects on Human Health
}

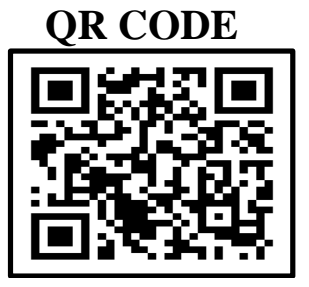

\section{SANJANA SETH' ${ }^{1}$, KASHMEERA AGARWAL $^{2}$, ABDUL RAHMAN $^{3}$}

Turmeric, commonly referred to as "Indian saffron" or the "golden spice", is a rhizomatous herbaceous perennial plant (Curcuma longa) and belongs to the ginger family. Spices made from the ground roots of the plant are available commercially. It has been used an active ingredient for formulating various medicinal preparations, and finds regular use in Ayurveda and Chinese medicine. Turmeric, and its constituent ingredients are being considered as multitargeted phytochemicals in the treatment of cancer as cell functions like apoptosis, autophagy, and cell cycle arrest are affected by its use. It has been shown to improve systemic markers of oxidative stress and its effect on free radicals is carried out by several different mechanisms. This brief review discusses the health benefits of curcumin as well as its medicinal use

KEYWORDS: Curcumin, Cancer, Arthritis, Antioxidant

\section{INTRODUCTION}

Turmeric, commonly referred to as "Indian saffron" or the "golden spice", is a tall plant commonly found growing in Asia and Central America. It is a rhizomatous herbaceous perennial plant (Curcuma longa) and belongs to the ginger family. ${ }^{1}$ Spices made from the ground roots of the plant are available commercially. Due to its bright yellow color(processed turmeric), it has inspired many cultures to use it as a dye. This spice has received great interest from both the medical/scientific worlds as well as from the culinary world. ${ }^{2}$

It is curcumin, a yellow polyphenolic pigment from the Curcuma longa L. (turmeric) rhizome, that has been used an active ingredient for formulating various medicinal preparations, and finds regular use in Ayurveda and Chinese medicine. Interestingly, this natural polyphenol is universally known as the "wonder drug of life".3 In India, turmeric, which containing curcumin, finds its regular use and consumption in curries, whereas in Japan, it is usually served in tea. It finds its use in the cosmetics industry in Thailand, while in China, it is used actively used as a colorant and in Korea, served in drinks. Malaysians use it as an antiseptic while in the United States, it is used in various preparations including mustard sauce, butter, cheese and chips. Curcumin is available in several forms including capsules, tablets, ointments, energy drinks, soaps, and cosmetics and is used in daily activities, albeit in many forms. ${ }^{3}$
In the far east, since ancient times, turmeric has been widely used for treating inflammations of various organs, for problems arising from the liver and digestive tract as well as to treat wound healing. During the 1970s, the first research on curcumin's health benefits was documented in the scientific literature. This particular study and studies conducted later reported the fact that curcumin has multiple therapeutic benefits and immense potential medicinal use. However, turmeric was still not commercially available and readily used as a therapeutic agent, ${ }^{4}$ due to its low bioavailability. It was reported that due to the hydrophobic nature of curcumin after oral administration, it triggers a poor absorption rate via the gastrointestinal (GI) tract. While on the other hand, curcumin offers a favourable and encouraging potential as it is categorized as a Generally Recognized As Safe (GRAS) material having a stable metabolism and low toxicity among humans. ${ }^{5}$

When used as a tonic for dyslipidaemia, stomach disorders, arthritis, hepatic diseases as well a wide variety of other diseases, it was found to provide immense benefits to the patients. ${ }^{6}$ Due to the immense benefits of curcumin listed above, this brief review discusses the health benefits of curcumin in daily as well as medicinal use.

\section{ANTICANCER PERSPECTIVES}

Turmeric, and its constituent ingredients are being 
considered as multitargeted phytochemicals in the treatment of cancer as cell functions like apoptosis, autophagy, and cell cycle arrest are affected by its use. ${ }^{7}$ Various authors have documented that various signalling pathways (e.g., P53, Ras, phosphoinositide 3 - kinase, AKT, Wnt/ $\beta$-catenin, and mammalian target of rapamycin) as the anticancer targets of curcumin. ${ }^{8}$

Colorectal Cancer (CRC): Curcumin can serve as an expedient remedy in the prevention of CRC among obese individuals by stimulating AMP-activated kinase by reducing the appearance of COX-2 protein and subsequently repressing the action of nuclear factor- $\kappa \mathrm{B}(\mathrm{NF}-\kappa \mathrm{B})$ on mucosal colon. It also diminishes leptin concentration in the serum and subsequently increases the adiponectin level. ${ }^{9}$

Renal Cancer: Long exposure of the cell lining of the human kidneys to $10 \mu \mathrm{M}$ curcumin have resulted in changes in the swelling-activated chloride current in a dose-dependent manner. Its application induces apoptosis in the human kidney cells by stimulating the emergence of a subpopulation of the cells with amplified volume at a concentration of $5.0-10 \mu \mathrm{M}$. Furthermore, $50 \mu \mathrm{M}$ curcumin has seen to initiate apoptosis and enlarge the size of colorectal adenocarcinoma cells; this cell cycle arrest is attributed to the fact which increases the size of the cell line after post-exposure to curcumin..$^{10}$

Hepatic Cancer: Curcumin has been reported to target the spindle assembly checkpoint which leads to initiation of apoptosis in cells having a higher concentration of phosphorylated cell division cycle 27 $\left(\mathrm{CDC}_{27}\right.$ ). This phosphorylation of $\mathrm{CDC}_{27}$ is the mechanism by which curcumin exerts its much beneficial anticancer effect. ${ }^{11}$

Bone Cancer: Curcumin has time and again proven its strong antiproliferative and anti-inflammatory properties, which is limited by its low water solubility. As per the results of a controlled study, the preparation and characterization of nanocurcumin using poly-lactic-co-glycolic acid significantly improved the water solubility and antitumor activity of curcumin. ${ }^{12,13}$

Blood and Other Cancers: The initiation of $\mathrm{G}_{2} / \mathrm{M}$ phase arrest by curcumin was the main reason for an evident reduction in the cyclin A, cyclin B, and cyclindependent kinase 1 protein expression. The apoptosis induction by curcumin is escorted with an upregulation of the Bax protein expression as well as the downregulation of the $\mathrm{Bcl}-2$ protein quantity resulting in mitochondria dysfunction, consequently leading to cytochrome c release and sequential activation of caspase- 9 and caspase- 3 in the nasopharyngeal carcinoma-TW o76 cells. As a result of this mechanism, mitochondria and apoptosisinducing factor caspase-3-dependent pathways are the fundamental figures in $\mathrm{G}_{2} / \mathrm{M}$ phase arrest and cell apoptosis by curcumin. ${ }^{44,15}$

\section{ANTIOXIDANT AND ANTI-INFLAMMTORY PROPERTIES}

Curcumin has been shown to improve systemic markers of oxidative stress and its effect on free radicals is carried out by several different mechanisms. ${ }^{15}$ It acts by scavenging different forms of free radicals, such as reactive oxygen and nitrogen species (ROS and RNS, respectively). ${ }^{16}$ In addition, curcumin is a lipophilic compound, which makes it an efficient scavenger of peroxyl radicals, therefore, like vitamin E, curcumin is also considered as a chainbreaking antioxidant. ${ }^{17}$ Curcumin has also been shown to suppress inflammation through many different mechanisms, thereby supporting its mechanism of action as a potential anti-inflammatory agent. ${ }^{18}$

\section{ARTHRITIS}

Once considered primarily a degenerative and noninflammatory condition with no cure, a few pharmaceutical therapies are available for treatment of osteoarthritis, many of which are costly and have undesirable side effects. Hence, patients tend to be inclined towards alternative treatments which include the intake of dietary supplements and herbal remedies. ${ }^{19}$ Several studies have shown the antiarthritic effects of curcumin in humans with Osteoarthritis (OA) and rheumatoid arthritis (RA).,20 Irrespective of the mechanism by which curcumin demonstrates its effects, it appears to be beneficial by healing several aspects of OA. Scientific evidence has reports that use of 8-12 weeks of standardized turmeric extracts (10oo $\mathrm{mg} /$ day) is beneficial in reducing arthritis symptoms (mainly pain and inflammation-related symptoms) and result in similar improvements in the symptoms as seen with common anti-analgesics like ibuprofen and diclofenac sodium. ${ }^{21}$

\section{METABOLIC SYNDROME}

Curcumin has been shown to attenuate several aspects of Metabolic Syndrome by improving insulin sensitivity ${ }^{22}$, suppressing adipogenesis ${ }^{2}$, decreasing blood pressure, inflammation and oxidative stress. ${ }^{22}$ 


\section{SIDE EFFECTS}

The natural, trustworthy curcumin has a longestablished safety record with the Allowable Daily Intake (ADI) as $\mathrm{o}^{-} \mathbf{3} \mathrm{mg} / \mathrm{kg}$ body weight [ as per JECFA (The Joint United Nations and World Health Organization Expert Committee on Food Additives) and EFSA (European Food Safety Authority)]. ${ }^{24}$ However, despite its impressive benefits, a few side effects have been reported among subjects receiving doses of 500-12,000 mg of curcumin and followed for 72 hours experienced diarrhea, headache, rash, and yellow stool as side effects. ${ }^{25}$ In the findings of Sharma RA et al., subjects receiving 0.45 to $3.6 \mathrm{~g} /$ day of curcumin between one to four months documented nausea and diarrhea with an increase in serum alkaline phosphatase and lactate dehydrogenase levels. ${ }^{26}$

\section{CONCLUSIONS}

Curcumin, which has been used since ancient times for its health benefits, has stood the test of time and is regularly used in treatment of various diseases, especially where herbal medicines are practiced. Following proper protocols, and proper patient selection, its use can be further encouraged as an alternative to allopathic medicines as it is cheaper and equally effective.

\section{REFERENCES}

1. Wilson DR. The positive and negative health effects of turmeric (Online Article). Available from https://www.medicalnewstoday.com/articles/318405.

[Last Accessed on 12 $^{\text {th }}$ September, 2021]

2. Hewlings SJ, Kalman DS. Curcumin: A Review of Its Effects on Human Health. Foods. 2017;6(10):92. https://doi.org/10.3390/foods6100092.

3. Gupta SC, Patchva S, Aggarwal BB. Therapeutic roles of curcumin: lessons learned from clinical trials. AAPS J. 2013;15(1): 195-218. https://doi.org/10.1208/s12248012-9432-8

4. Gera M, Sharma N, Ghosh M, Huynh DL, Lee SJ, Min T, Kwon T, Jeong DK. Nanoformulations of curcumin: an emerging paradigm for improved remedial application. Oncotarget. 2017; 8(39):66680-98. https://doi.org/10.18632/oncotarget.19164

5. Nelson KM, Dahlin JL, Bisson J, Graham J, Pauli GF, Walters MA. The Essential Medicinal Chemistry of Curcumin. J Med Chem. 2017;60(5):1620-37. https://doi.org/10.1021/acs.jmedchem.6boog75

6. Delgado-Vargas F, Paredes-López O. Natural Colorants for Food and Nutraceutical Uses, CRC Press, Boca Raton, FL, USA, 2002.
7. Zhu Y, Bu S. Curcumin induces autophagy, apoptosis, and cell cycle arrest in human pancreatic cancer cells. Evidence-Based Complementary and Alternative Medicine 2017;2017:5787218. https://doi.org/10.1155/2017/5787218

8. Ahmad RS, Hussain MB, Sultan MT, Arshad MS, Waheed M, Shariati MA, et al. Biochemistry, Safety, Pharmacological Activities, and Clinical Applications of Turmeric: A Mechanistic Review. Evidence-Based Complementary and Alternative Medicine 2020;2020: 7656919. https://doi.org/10.1155/2020/7656919

9. Chen MJ, Cheng YM, Lai PH, Wu JF, Hsu YC. In vitro biocompatibility of thermally gelling liquid mucoadhesive loaded curcuminoids in colorectal cancer chemoprevention. International Journal of Colorectal Disease 2012;27(7):869-78.

10. Yu J, Zhou X, He X, Dai M, Zhang Q. Curcumin induces apoptosis involving bax/bcl-2 in human hepatoma SMMC-7721 cells. Asian Pac J Cancer Prev, 2011;12(8):1925-9.

11. Lee SJ, Langhans SA. Anaphase-promoting complex/cyclosome protein $\mathrm{Cdc}_{27}$ is a target for curcumin-induced cell cycle arrest and apoptosis. BMC Cancer 2016; 12(1):44.

12. Nair KL, Thulasidasan AK, Deepa G, Anto RJ, Kumar GS. Purely aqueous PLGA nanoparticulate formulations of curcumin exhibit enhanced anticancer activity with dependence on the combination of the carrier. Int J Pharm. 2012 Apr 4;425(1-2):44-52. https://doi.org/10.1016/j.ijpharm.2012.01.003.

13. Yin $\mathrm{H}$, Guo $\mathrm{R}, \mathrm{Xu} \mathrm{Y,}$, Zheng $\mathrm{Y}$, Hou Z, Dai X. Synergistic antitumor efficiency of docetaxel and curcumin against lung cancer. Acta Biochimica et Biophysica Sinica, 2012; 44(2):147-53. https://doi.org/10.1093/abbs/gmrio6.

14. Kuo CL, Wu SY, Ip SW, Wu PP, Yu CS, Yang JS, et al. Apoptotic death in curcumin-treated NPC-TW o76 human nasopharyngeal carcinoma cells is mediated through the ROS, mitochondrial depolarization and caspase-3-dependent signalling responses. International Journal of Oncology 2011;39(2):319-328. https://doi.org/10.3892/ijo.2011.1057

15. Sahebkar A, Serbanc MC, Ursoniuc S, Banach M. Effect of curcuminoids on oxidative stress: A systematic review and meta-analysis of randomized controlled trials. J Funct Foods. 2015;18:898-909. https://doi.org/10.1016/j.jff.2015.01.005

16. Menon VP, Sudheer AR. Antioxidant and antiinflammatory properties of curcumin. Adv Exp Med Biol. 2007;595:105-125.

17. Priyadarsini KI, Maity DK, Naik GH, Kumar MS, Unnikrishnan MK, Satav JG, et al. Role of phenolic O$\mathrm{H}$ and methylene hydrogen on the free radical 
reactions and antioxidant activity of curcumin. Free Radic Biol Med. 2003;35:475-84.

18. Panahi Y, Hosseini MS, Khalili N, Naimi E, Simental-Mendía LE, Majeed M, Sahebkar A. Effects of curcumin on serum cytokine concentrations in subjects with metabolic syndrome: A post-hoc analysis of a randomized controlled trial. Biomed Pharmacother. $2016 \quad$ Aug;82:578-82. https://doi.org/10.1016/j.biopha.2016.05.037.

19. Sahebkar A. Molecular mechanisms for curcumin benefits against ischemic injury. Fertil Steril. 2010;94:e75-e76.

20. Belcaro G, Cesarone MR, Dugall M, Pellegrini L, Ledda A, Grossi MG, Togni S, Appendino G. Productevaluation registry of Meriva $^{\circledR}$, a curcuminphosphatidylcholine complex, for the complementary management of osteoarthritis. Panminerva Med. 2010;52(2 Suppl 1):55-62.

21. Daily JW, Yang M, Park S. Efficacy of Turmeric Extracts and Curcumin for Alleviating the Symptoms of Joint Arthritis: A Systematic Review and MetaAnalysis of Randomized Clinical Trials. J Med Food. 2016 Aug;19(8):717-29. https://doi.org/10.1089/jmf.2016.3705.
22. Chuengsamarn S, Rattanamongkolgul S, Luechapudiporn R, Phisalaphong C, Jirawatnotai S. Curcumin extract for prevention of type 2 diabetes. Diabetes Care. $2012 \quad$ Nov;35(11):2121-7. https://doi.org/10.2337/dc12-0116.

23. Bradford PG. Curcumin and obesity. Biofactors 2013;39:78-87.

24. Kocaadam B, Şanlier N. Curcumin, an active component of turmeric (Curcuma longa), and its effects on health. Crit Rev Food Sci Nutr. 2017 Sep 2;57(13):2889-2895.

https://doi.org/108o/10408398.2015.1077195.

25. Lao CD, Ruffin MT $4^{\text {th }}$, Normolle D, Heath DD, Murray SI, Bailey JM, et al. Dose escalation of a curcuminoid formulation. BMC Complement Altern Med. 2006 Mar 17;6:10. https://doi.org/10.1186/14726882-6-10.

26. Sharma RA, Euden SA, Platton SL, Cooke DN, Shafayat A, Hewitt HR, Marczylo TH, Morgan B, Hemingway D, Plummer SM, Pirmohamed M, Gescher AJ, Steward WP. Phase I clinical trial of oral curcumin: biomarkers of systemic activity and compliance. Clin Cancer Res. 2004;10(20):6847-54. https://doi.org/10.1158/1078-0432.CCR-04-0744. 